\title{
ABRAHAM E ISAAC, PERSONAJES DE UNA EPIFANÍA EN UNA COMUNIDAD INDÍGENA DE YUCATÁN
}

\author{
ÓSCAR ARMANDO GARCÍA GUTIÉRREZ
}

\section{RESUMEN}

En el poblado de Dzitnup, en el oriente de Yucatán, se asienta una comunidad campesina maya parlante que ha preservado una tradición centenaria: la celebración anual, desde la Navidad hasta la Epifanía, de una danza dialogada de Abraham e Isaac.

Esta danza se lleva a cabo en el atrio y en el interior de la pequeña iglesia parroquial del lugar. El propósito de esta danza es mostrar la manera en que Abraham e Isaac protegen al Niño Dios (que se encuentra en un pesebre en el interior de la iglesia) del posible rapto del Diablo o del Mal. Participan tres ejecutantes en la representación y constantemente interactúan con el público asistente, principalmente con los niños.

La pregunta es: ¿qué relación pueden tener Abraham e Isaac con las celebraciones navideñas? ¿Se trata de una espontánea adaptación de los indígenas mayas a la liturgia cristiana o podríamos estar ante un festejo con posibles antecedentes medievales? Trataremos de hacer un recorrido histórico de los procedimientos de evangelización en Yucatán en los siglos XVI y XVII para poder rastrear una comunicación entre esos acontecimientos y las fiestas que actualmente celebran los indígenas mayas. El artículo explicará la estructura de la celebración y tratará de plantear las diversas fuentes de esta peculiar fiesta yucateca.

\section{ABRAHAM AND ISAAC: CHARACTERS IN AN EPIPHANY IN A YUCATAN INDIGENOUS COMMUNITY}

\footnotetext{
ABSTRACT

In the village of Dzitnup, in the eastern Yucatan, lives a Mayan-speaking peasant community which has kept a centenary tradition: the annual dialogued dance celebration from Christmas to the Epiphany between Abraham and Isaac.

This dance, performed in the atrium and interior of the small parish church, aims to show how Abrabam and Isaac protect Baby Jesus (in a crib inside the church) from a possible kidnapping by the Devil and from Evil. Three performers take part in the representation and constantly interact with the attending public, principally with children.

The question is: What relationship could Abraham and Isaac bave with the Christmas festivities? Is it a spontaneous adaptation of Mayan Indians to Christian liturgy or might we be witness to a festival with possible mediaeval antecedents? An historical trace of evangelist procedures in Yucatan in the $16^{\text {th }}$ and $17^{\text {th }}$ Centuries will be attempted in order to track a link between those events and the festivals presently celebrated by the Mayan Indians. The article will lay out the celebration's structure and attempt to suggest the diverse sources behind this particular Yucatan feast.
}

Óscar Armando García

Gutiérrez

Licenciado en Literatura Dramática y Teatro por la Universidad Nacional Autónoma de México. Maestro en Historia por la Universidad Católica de Lovaina (Bélgica). Doctor en Historia del Arte por la UNAM. Sus lineas fundamentales de investigación giran en tomo al espacio teatral, en especial en el período novohispano; a este tema ha dedicado numerosos trabajos en publicaciones mexicanas e internacionales. Como especialista en teatro mexicano, participa además en los consejos editoriales de las revistas Escénica, Extensión y Espacio Escénico. Ha impartido docencia en la Escuela Nacional de Arte Teatral del INBA, la Universidad Iberoamericana, el Institut del Teatre de Barcelona y Universidad de Perpignan (Francia). Ha sido Director fundador del Centro de Investigaciones Escénicas de Yucatán (CINEY) del Instituto de Cultura de Yucatán. Actualmente es Profesor a Tiempo Completo en la Facultad de Filosofía y Letras de la UNAM, investigador en el Sistema Nacional de Investigadores de México y Presidente de la Asociación Mexicana de Investigación Teatral (AMIT).
Abraham e Isaac, personajes de una Epifanía en una comunidad indígena de Yucatán

OSCAR ARMANDO GARCÍA GUTIERREZ 


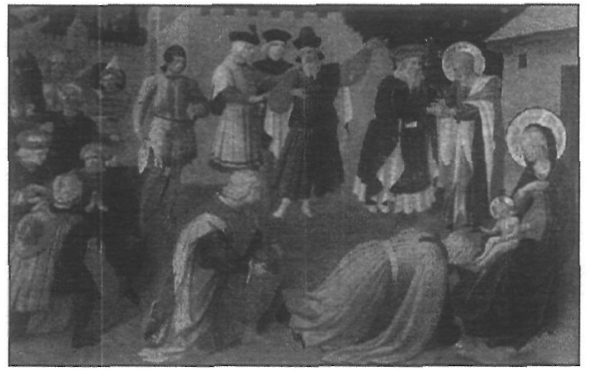

La Adoración de los Magos. Anónimo siglo XV.
En Dzitnup, pequeño poblado del oriente de Yucatán (a unos cuantos kilómetros de la ciudad de Valladolid), se asienta una comunidad campesina maya-parlante que ha preservado una tradición centenaria: la celebración anual (en la Navidad y la Epifanía) de una danza dialogada, denominada Abraham e Isaac.

La fiesta ha sido motivo de múltiples 1 Luis Pérez Sabido (Bailes y danzas tradicionales de Yucatán, Mérida, DIF-Yucatán, 1983) hizo uno de los primeros trabajos de análisis y recopilación de esta fiesta; Fernando Muñoz (Tea tro maya peninsular, Mérida Ayuntamiento de Mérida, 2000 considera en su trabajo la hipótesis de que este evento podría tener un enlace con la pieza de teatro evangelizador El sacrificio de Isaac y Donald Frischmann («Transformaciones y trascendencia en el arte ritual y escénico de los mayas peninsulares», Investigación Teatral, núm. 5, enero-junio 2004, págs. 9-20) postula que las fuentes de esta celebración son sustancialmente de origen indígena.

2

Cf. Armando García Gutiérrez, «Los espacios escénicos en Tikal» en Cuadernos de Arquitectura Mesoamericana, (División de Estudios de Posgrado. Facultad de Arquitectura. UNAMI, núm. 6, noviembre 1985, págs. 69-86

3

Cf. Óscar Armando García, «La capilla abierta: espacio, representación y poder institucional en la Nueva España» en Daniel Meyran, Alejandro Ortiz y Francis Sureda (eds.), Teatro y poder, Perpignan, Presses Universitaires de Perpignan, Collection Études, 2002, págs. 285-296.

4

Nos basaremos principalmente en la investigación de Peter Gerhard La frontera sureste de la Nueva España, México, UNAM, 1991, y en el trabajo historiográfico de Stella Ma. González Cicero, Perspectiva religiosa en Yucatán, 1517 1571, México, El Colegio de México, 1978

Abraham e Isaac, personajes de una Epifanía en una comunidad indígena de Yucatán

ÓSCAR ARMANDO

GARCIA GUTIÉRREZ análisis por parte de algunos investigadores quienes, en su momento, han planteado diversas hipótesis sobre los orígenes, influencias y formato de esta celebración ${ }^{1}$; sin embargo el objetivo particular del presente artículo es desentrañar otra faceta de la fiesta: sus posibles vínculos con celebraciones medievales europeas. Ante esta representación, el espectador actual podría preguntarse qué relación pueden tener los personajes de Abraham e Isaac con las celebraciones navideñas y si se trata de una espontánea adaptación de los indígenas mayas a la liturgia cristiana o podríamos estar ante un festejo con posibles antecedentes medievales. Este trabajo tratará de proponer puentes explicativos diferentes para poder dilucidar el sentido de esta singular celebración.

\section{ALGUNAS EXPRESIONES DE TEA- TRALIDAD INDÍGENA MAYA}

La cultura maya es, sin duda, una de las más esplendorosas de la historia. A medida que avanzan los descubrimientos arqueológicos y se analiza la compleja estructura de su civilización, vamos comprendiendo los impresionantes avances que los mayas tuvieron dentro del conocimiento en general (matemáticas, astronomía, escritura, arquitectura, escultura, pintura, etcétera). Su complejidad cultural fue correspondiente a su complejidad religiosa, paralela al resto de las culturas mesoamericanas, dentro del denominado periodo clásico (siglos IX al XIII de nuestra era). Esta religiosidad era el centro de sus actividades, lo que llevó a los mayas a consolidar una compleja red de celebraciones rituales, bajo un severo cumplimiento calendárico.

Dentro de la región mesoamericana, fue de los mayas de quienes contamos con el único vestigio de un diálogo que pudo haber tenido cercanía formal con aquello que nosotros denominamos drama: el Rabinal Achi. No obstante, también tenemos otros vestigios que nos confirman que los mayas tuvieron entre sus fiestas algo que pudo haber tenido un formato análogo al teatro occidental. Estos vestigios son, principalmente, algunas representaciones de disfraces en registros iconográficos (estatuillas de Jaina o los murales de Bonampak), o bien el uso de explanadas que fueron utilizadas como espacios de representación ritual colectiva, con graderías para espectadores y un área de actividad, tal fue el caso de los Complejos Gemelos y la Arena en Tikal, o bien ciertas plazas de otras ciudades del área como Copán, Chichén Itzá y Dzibilchaltún ${ }^{3}$.

Antes de continuar con esta revisión, es necesario apuntar que, cuando mencionamos el concepto de teatralidad maya, nos estamos refiriendo a una continuidad festiva que tiene vigencia en la región. Los mayas que hoy habitan la península de Yucatán y parte de Centroamérica (varios de ellos descendientes directos de los mayas prehispánicos), tienen como particularidad el desarrollo de una compleja ritualidad, producto de su principal oficio: el cultivo de la tierra. Estamos ante una cultura de la tierra que sigue celebrando puntualmente (como toda comunidad agrícola) los ritmos propios del proceso cíclico de la labranza. Alrededor de este ciclo, el pueblo maya ha desarrollado una serie de fiestas (acorde con los principales onomásticos cristianos) que nos ofrecen su peculiar concepción de un mundo mítico.

\section{BREVE SEMBLANZA DE LA CON- QUISTA Y EVANGELIZACIÓN EN YU- CATÁN ${ }^{4}$}

Para una mejor comprensión de la fiesta que analizaremos posteriormente, nos parece pertinente hacer un breve repaso sobre los principales acontecimientos de los procesos de evangelización en el área de Yucatán. La especificidad de estos procesos podría ofrecernos algunas pistas significativas sobre las maneras en que la ritualidad popular maya se fue configurando a través de diferentes factores, entre ellos la incursión de la ritualidad religiosa europea en la región.

Desde las primeras incursiones españolas por territorio mesoamericano hechas por Hernández de Córdoba, Juan Grijalva y Hernán Cortés (entre 1517 y 1519), esta zona fue considerada solamente un buen punto estratégico para los trayectos de las expediciones hispanas provenientes de la isla de Cuba. Esto explica que la colonización de Yucatán 
se iniciara de manera tardía, a comparación de otras regiones, como el Altiplano, Occidente y Guatemala.

Podemos dar como fecha del inicio de la colonización de Yucatán el 8 de diciembre de 1528, cuando la expedición de Francisco de Montejo hizo posible la capitulación del poblado indígena de T'Ho (actual Mérida), pero no será sino hasta el 6 de enero de 1542 cuando oficialmente se funde Mérida como ciudad hispana. Este hecho confirma la poca importancia que había tenido la región, tanto para conquistadores como para los gobiernos virreinales, pues Yucatán no se encontraba entre las zonas prioritarias para la explotación de recursos naturales, tan vitales para la corona española. Los religiosos habían acompañado a los capitanes y soldados en estas incursiones; sin embargo, la primera visita a la zona hecha por un franciscano será la de fray Jacobo de Tastera en 1537, quien preparará el camino de los primeros procesos de evangelización de la región. Para 1544, Mérida estuvo comprendida dentro del territorio de la Provincia del Santo Evangelio.

En 1545 llegan a la Península de Yucatán los frailes franciscanos Luis de Villalpando, Melchor de Benavente y Juan de Herrera, enviados por fray Toribio Motolinía ${ }^{5}$ desde Chiapas. Un cuarto fraile, Lorenzo de Bienvenida, llegaría ese año a territorio yucateco desde Guatemala, vía Bacalar, lugar donde estableció una incipiente misión. Los tres primeros se encargarán de preparar la fundación del convento de San Francisco de Campeche (1545), la misión de Mérida (1546) y la misión de Maní (1547), junto con las primeras tareas de adoctrinamiento entre la población indígena, conformándose de esta manera la primera ruta misionera de Yucatán. En 1548, los franciscanos yucatecos son nombrados Procuradores por la misma orden, acontecimiento que sienta un precedente especial para los futuros procesos de secularización en décadas posteriores.

En 1549 se realiza el primer capítulo custodial de Mérida. Para entonces, existen ya establecidos cinco conventos (construidos aún de palma, madera y adobe): Mérida, Campeche, Maní, Izamal y Conkal. La región se separa de la Provincia del Santo Evangelio y se convierte en la Custodia de San José. Ese año también llega a tierras yucatecas fray Diego de Landa, quien comienza la construcción de conventos en piedra. En Izamal, Landa encuentra el sitio adecuado para la construcción de un convento y un seminario.
1561 será un año decisivo para los procesos de evangelización en Yucatán, pues se elige a Diego de Landa como Provincial de San José de Yucatán y, a la vez, es el momento de la llegada del obispo Francisco del Toral, iniciándose con ello la secularización de la región. Un año después, Landa realiza el proceso de Manít. Este polémico incidente lo lleva de retorno a España, para volver en 1572 como obispo de Yucatán. Para 1571 llega el último grupo de franciscanos peninsulares, entre ellos fray Blas Cotello.

La historia de la misión franciscana

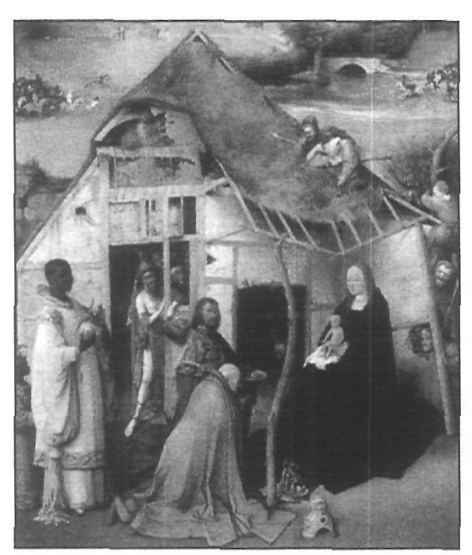

La adoración de los Reyes Magos. El Bosco (detalle). 1510. Museo del Prado. en Yucatán debe revisarse junto con la historia de la secularización, fenómeno común en diversas regiones durante el siglo XVI en la Nueva España7. No será sino hasta 1560 que se designa al fraile franciscano Francisco de Toral como encargado del Obispado de Yucatán. Cuando Toral llegó a Yucatán, condenó principalmente que los franciscanos se hubiesen atribuido funciones de inquisidores en el proceso contra idolatría de Maní. Los franciscanos yucatecos tenían como defensa el haber sido nombrados procuradores, lo que les permitía articular juicios contra la idolatría. Toral, quien había tenido experiencias evangelizadoras con los nahuas del Altiplano, criticó los métodos utilizados por los franciscanos de la Provincia de Yucatán; por lo tanto, estableció el fortalecimiento de instrucciones como el bautismo, la pila bautismal oculta, la doctrina, la ejecución de bailes durante el día y la construcción de una cerca alrededor de los atrios conventuales para impedir el paso de las bestias. La etapa más intensa de su trabajo episcopal se dio entre el 1561 y el 1569 .

En resumen, la evangelización de Yucatán en el siglo XVI, aunque tardía con respecto al resto de las provincias, tuvo también la participación activa de religiosos que ya habían tenido experiencias evangelizadoras en otras regiones, y que consolidaron paulatinamente la occidentalización de la zona a través de su labor de conversión religiosa.

\section{DZITNUP, PRIMER REGISTRO POR PARTE DEL PADRE PONCE}

Uno de los registros hispanos más tempranos de la población de Dzitnup que conservamos es la noticia que el padre Ponce registrará en su relación de la siguiente manera:
5

Nombre indígena de fray To ribio de Benavente, el célebre franciscano autor de la Historia de los indios de la Nueva España, relato que recopila su experiencia principalmente en la ciudad de Tlaxcala en años anteriores.

6

Fray Diego de Landa manda a los caciques mayas que traigan a Maní todos los códices e ídolos que tuvieran escon didos para prenderles fuego en una enorme hoguera. Con ello se perdieron documentos valiosos de la historia de los mayas pero, paradójicamente, Landa también tuvo el impulso de conservar esa historia en su obra Relación de las cosas de Yucatán a través de diversos informadores indígenas. Esta crónica recoge algunos signos de la compleja escritura maya a partir de lo cual se han podido hacer los mejores trabajos de desciframiento de los jeroglíficos mayas.

7

Ya desde el 1518 se comienzan las primeras negociaciones para proveer a Yucatán de un obispo, pero por una confusión cartográfica se deshecha la idea. La primera presencia secular en la región será un tanto casual, cuando en 1545 pasa Bartolomé de las Casas por la región, camino a Ciudad Real (Chiapas).

Abraham e Isaac, personajes de una Epifanía en una comunidad indígena de Yucatán ÓSCAR ARMANDO GARCÍA GUTIÉRREZ 


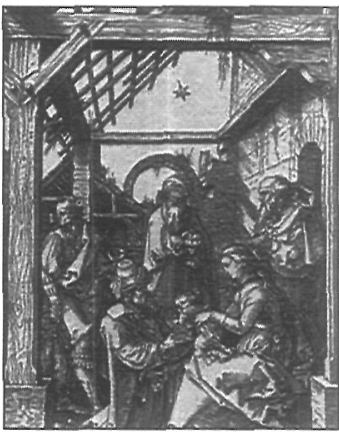

Adoración de los Reyes. Alberto Durero. Grabado. 1511.

8

Antonio de Ciudad Real, Tratado curioso y docto de las grandezas de la Nueva España, México, UNAM, 1993, tomo II, pág. 327

9

Ciudad yucateca cercana al norte de Valladolid, en donde la iglesia tiene como advocación principal a los Reyes Magos. Las imágenes son ampliamente veneradas por los habitantes de la región.

\section{0}

Principalmente el canto de villancicos es interpretado por mujeres, por lo tanto en sentido estricto estaríamos ante «Pastoras». Esto sucede en otras pastorelas indígenas, como la que se desarrolla en Santa Fe de la Laguna, en la zona lacustre de Michoacán.

Abraham e Isaac, personajes de una Epifanía en una comunidad indígena de Yucatán

OSCAR ARMANDO GARCÍA GUTIÉRREZ
Jueves veintiocho de julio [1588] salió [el padre Ponce] de Zaquí [actual Valladolid] a las dos de la mañana, y andada una legua de razonable camino llegó a un pueblo de aquella guardianía llamado Citmop, donde aunque era muy de noche, le estaban los indios aguardando con muchas ramadas y dos danzas, una de mochachos y otra de indios grandes. Pasó adelante después de haberles agradecido su devoción...8.

El pasaje es interesante por varios motivos. El primero es que, desde finales del siglo XVI, la población tenía una conexión importante con Zaquí, actual ciudad de Valladolid. El siguiente es que Ponce haya sido recibido justamente con «ramadas» y «danzas» por parte de muchachos y adultos mayas, como si esta manera de festejo tuviera una suerte de continuidad hasta nuestros días. Sin embargo, este posible nexo se pierde por la falta de otros registros en siglos posteriores. No será sino hasta fines del siglo XIX cuando se recuperan los referentes más remotos de la fiesta que nos ocupa.

\section{DESCRIPCIÓN DE LA FIESTA DEL ABRAHAM E ISAAC DE DZITNUP}

La fiesta de Abraham e Isaac se lleva a cabo en el atrio y en el interior de la pequeña iglesia parroquial de Dzitnup, hoy una pequeña comunidad maya dedicada a las labores del campo. Si quisiéramos hablar de un argumento en concreto de esta representación sería la manera en que Abraham e Isaac protegen al Niño Dios (que se encuentra en un pesebre en el interior de la iglesia) del posible rapto del Diablo o del Mal. Participan tres ejecutantes en la representación que constantemente interactúan con el público asistente, principalmente con los niños. En sí, Abrabam e Isaac es una representación compleja en donde se manifiestan y funden expresiones reconocibles de danza, procesión, juegos, música y diálogos durante la celebración.

La representación se lleva a cabo en la noche del 24 de diciembre y del 5 de enero, para amanecer al siguiente día. El festejo es organizado por un selecto grupo de ancianos de la comunidad que se proclaman como mayordomos de la parroquia dedicada a san Andrés. Como dato revelador, el párroco no oficia durante estos días ni está presente como espectador. No se tiene un cálculo certero desde cuándo se lleva a cabo este evento, pero, como mencionamos con anterioridad, los investigadores que han trabajado el tema plantean dos posibilidades: su celebración centenaria desde tiempos remotos o bien que se trate de una conmemoración de unos ciento cincuenta años aproximadamente. Lo cierto es que estos cálculos requieren de una mayor documentación e indagación. A manera de recorrido general, las partes principales de la fiesta son:

\section{Novenario}

Al ocultarse el sol, un grupo de mujeres se reúne en el interior de la parroquia para iniciar el rezo y canto de villancicos, alternados en maya y en español. El novenario es el que se dedica tradicionalmente a los Reyes Magos de Tizimín" por parte de los «Pastores» o rezanderos ${ }^{10}$.

\section{Sacristía}

En la sacristía se han dado cita los danzantes de la fiesta (a manera de camerino), en donde se visten y se preparan. Los personajes son Abraham, Isaac y el Mal o Diablo. Generalmente se mantiene en secreto la identidad de los danzantes. De la puerta que da acceso al interior del templo surgen los personajes de Abraham e Isaac con velas e inician la procesión de fieles por el pasillo central, desde el altar hasta la puerta principal de la parroquia. El Mal sale por la puerta que da al exterior para realizar paralelamente sus rutinas en el atrio.

\section{Juegos en el atrio}

De manera simultánea, en el atrio de la parroquia el Diablo/el Mal comienza a interactuar con los niños, quienes en un juego han desmembrado al Mal; las partes han sido repartidas entre la población de manera simbólica y lúdica. El proceso lúdico del desmembramiento inicia con una rutina del Mal quien, con su bastón, gira en su eje durante unas trescientas veces. Cuando termina, exhausto, algún integrante de la comunidad realiza el mercadeo de las partes del Mal, lo que permite una interrelación con los niños cuando las partes son subastadas por medio de diálogos picarescos.

\section{Puerta del templo}

Cuando Abraham e Isaac llegan a la puerta, cruzan el umbral, se voltean hacia el altar y se sitúan unos pasos fuera del templo. Los fieles, dentro del templo, permanecen viendo todo esto hacia el exterior, en el límite que marca la puerta principal.

Los fieles inician un canto de villancicos con exaltación a la Sagrada Familia, mientras 
Abraham e Isaac ejecutan una danza, emulando el trote de un caballo. Este ritmo es acompañado por el tunkul (tambor de madera) que se encuentra en el atrio exterior (pero cercano a la escena). Participan también las campanas de la parroquia, las cuales contrapuntean rítmicamente con el tunkul y el trote de los personajes, en un espectacular y complejo diálogo de sonidos, textos, ritmos y formas.

En este momento, cumbre tal vez, de la danza, los participantes (fieles y danzantes) marcan espacialmente dos áreas de representación de manera dialógica: el interior del templo y el atrio exterior. En el interior se cantan villancicos y se localiza, resguardada, la imagen del Niño Dios; en el exterior se encuentran los danzantes que defienden al Niño (Abraham e Isaac), el danzante que amenaza (el Mal), los niños y el tambor indígena.

Posteriormente, Abraham e Isaac simulan con bastones una batalla contra el Mal con bailes grotescos en el atrio. Los niños rodean el baile/juego. El 24 de diciembre este juego escénico lo ejecutan los Doce Apóstoles (doce adolescentes), quienes, a través de una ronda, impiden al Mal atacar a Abraham e Isaac y, por consecuencia, al Niño Dios que se encuentra «resguardado» en un pesebre dentro del templo. El Mal ha sido eliminado y desmembrado por la comunidad a través de los juegos anteriormente mencionados. Al finalizar esta batalla, todos los fieles, acompañados por Abraham e Isaac, se dirigen al altar.

\section{Ofrecimiento}

El Mayordomo de la fiesta se dirige al altar y toma la imagen del Niño Dios. Esta imagen es transportada en un capelo de tela blanca y es ofrecida a los fieles en alto, de manera análoga al ofrecimiento del Santísimo Sacramento en la liturgia. La diferencia es el espacio, pues este ofrecimiento no se hace en el altar, sino en el arranque del pasillo central del templo.

\section{Procesión}

Después del ofrecimiento del Niño Dios, un grupo selecto de fieles (o rezanderos) se dirige al altar y toman las imágenes de José, la Virgen María, los tres Reyes Magos y la Cruz, que toma la delantera para iniciar una procesión al interior del templo. La procesión consta de seis vueltas en el pasillo central desde el altar hasta la puerta de la iglesia. Al finalizar la procesión, los integrantes depositan de nuevo las figuras en el altar. Con esto finaliza el evento nocturno ${ }^{11}$.

\section{Recolta del aguinaldo}

A la mañana siguiente, los jóvenes que han interpretado a Abraham, Isaac y el Mal (aún disfrazados) recorren las calles del pueblo para iniciar la recolta del aguinaldo, en una pequeña procesión en donde se integran: el mayordomo de la fiesta portando a la imagen del Niño Dios, músicos y sobre todo niños de la comunidad. El procedimiento de esta etapa es el siguiente:

Abraham e Isaac se presentan ante la puerta de la casa de alguno de los vecinos para recibir una medida (1/2 kilogramo aproximadamente) de granos de maíz o frijol, la cual es depositada en una carretilla. Mientras tanto, el Mal incursiona en el huerto de la casa para robarse los frutos, principalmente naranjas, las que acumula en una manta. Los niños que acompañan la procesión juegan a descubrir la fechoría del Mal, quien huye por la calle, mientras lanza naranjas a los niños que corren tras él.

Los personajes de Abraham e Isaac interpretan una pequeña danza (con ritmo de jota) en el portal de cada casa, en agradecimiento a la contribución hecha por el vecino. Con este baile inicia el desplazamiento a otra casa de la comunidad para repetir el acto antes descrito.

Al finalizar la jornada se reúne todo el grano recabado para ser vendido en el mercado. La ganancia de lo que fue vendido se guarda para los gastos de la fiesta del siguiente año.

\section{PERSONAJES DE LA FIESTA}

\section{Abraham}

También denominado Suku'n (hermano mayor $)^{12}$. Utiliza una máscara de madera con marcas de arrugas en el rostro, para enfatizar la edad del personaje. Las máscaras de Abraham e Isaac son elementales en su confección y sus formas, sin embargo son excepcionales en la región, debido a que en todo Yucatán no existen otras manifestaciones escénico-dancísticas donde se utilicen máscaras.

\section{Isaac}

Su denominación en maya es Its'in (hermano menor) ${ }^{13}$. Según Frischmann es posible que el parecido fonético del nombre en maya del personaje haya generado la tradición de representarlo e identificarlo como «Isaac». Pero existe un dato aún más revelador: en su máscara encontramos labrada una estrella en la frente, la cual representa la estrella de Belén, según información directa de don Eustaquio

\begin{abstract}
11
Según varios testimonios, la fiesta generalmente tiene una duración aproximada de doce horas; sin embargo, cuando ruvimos la oportunidad de presenciar este evento (enero 2003), culminó alrededor de la una de la madrugada, porque al día siguiente los niños y jóvenes tenían cursos en las escuelas. Existen algunos registros videográficos de esta fiesta que han sido filmados en diversas ocasiones durante las dos últimas décadas del siglo $X X$ y principios del $X X l$, entre los que destacan: La danza de Abraham e /saac (Dzitnup), 24 de diciembre 1998, Instituto de Cultura de Yucatán y El protector de la luz, realización de Óscar Urrutia, Dirección de Comunicaciones / Dirección de Artes Escénicas / CINEY / Instituto de Cultura de Yucatán (2003). Estos materiales se encuentran en el acervo videográfico del Centro de Investigaciones Escénicas de Yucatán (CINEY)
\end{abstract} en Mérida

12

Frischmann, op. cit., pág. 15.

13

Ibidem.
Abraham e Isaac, personajes de una Epifanía en una comunidad indígena de Yucatín

ÓSCAR ARMANDO

GARCIA GUTIERREZ 
Don Eustaquio Poot es el actual responsable de la mayordomía de la fiesta y también es el tallador de las máscaras en madera de Isaac y Abraham.

15

Frischmann, op. cit., pág. 15.

16

Este trabajo exegético fue realizado en colaboración con Diana Torres.

17

Relación que aparece en las interpretaciones de la Biblia desde los Santos Padres y también en la tradición teatral medieval, aspecto sobre el que intentaremos profundizar en fuluros trabajos.

18

Cf. Luis Astey, Dramas litúrgicos del occidente medieval. México, México, El Colegio de México, 1992.

19

No sería aventurado pensar que la situación fronteriza de esta fiesta portuguesa con España haya podido facilitar su comunicación a tierras americanas. La noticia de este evento fue transmitida al autor por el doctor Francesc Massip en noviembre de 2004 en Barcelona.

20

También denominada popularmente en México como «Nacimiento».

Abraham e Isaac, personajes de una Epifanía en una comunidad indígena de Yucatán

ÓSCAR ARMANDO

GARCÍA GUTIÉRREZ
Poot ${ }^{14}$. Tanto Isaac como Abraham visten una túnica corta azul y pantalones de mezclilla. Los dos personajes portan sendas varas a manera de bastones.

\section{El Mal}

Este personaje es identificado por la comunidad como K'akas ba'al (cosa maligna y fea/Diablo $)^{15}$. A diferencia de los dos anteriores, este personaje lleva una máscara de animal, sin definición entre una figura equina o porcina, confeccionada en piel. Porta una especie de overol que permite ubicarlo dentro de un ámbito menos extraordinario que los otros dos personajes bíblicos.

\section{RELACIÓN TEMÁTICA ENTRE LOS PERSONAJES BÍBLICOS DE ABRA- HAM, ISAAC Y CRISTO}

Nos parece oportuno, para el análisis de esta fiesta, destacar la relación existente entre Abraham e Isaac y la figura de Jesús; es decir, la conexión entre pasajes del Antiguo y Nuevo Testamento que permiten ofrecer una identificación entre los personajes ${ }^{16}$ :

La Nueva Alianza entre Abraham y Yahvé se encuentra presente en Génesis 15 y el nacimiento de Isaac en Génesis 21. En los Evangelios se hallan aquellos pasajes que describen los principales acontecimientos de la vida de Cristo.

Si analizamos los pasajes, Isaac es un equivalente de Cristo porque los dos fueron «corderos» ofrecidos en sacrificio por sus respectivos padres. Sin embargo, existe una primera diferencia: Abraham no concluye el sacrificio porque Yahvé (por medio del ángel) lo detiene; por su parte Cristo es sacrificado sin la oposición de Yahvé, y no existirá quien detenga este acontecimiento.

Los dos hijos (Isaac y Cristo) son pastores de ovejas. Incluso podríamos encontrar una curiosa semejanza: el sacrificio de Isaac iba a llevarse a cabo con una herida en el costado, mientras que la última herida de Cristo es hecha por un soldado, con la punta de la lanza, en un costado. De esa herida no sale sangre sino agua.

Finalmente, los dos son varones, son hijos únicos, son inocentes, libres de pecado y obedecen a sus padres por amor a ellos.

¿Sería posible entonces estar en Dzitnup ante una fiesta en donde se interpretó adecuadamente esta relación ${ }^{17}$ ? No tenemos una respuesta sólida; sin embargo, lo que podría parecer un desatino interpretativo (Abraham e Isaac en una Epifanía), podría comenzar a tener una lógica sustancial dentro del panorama ritual-religioso de una comunidad indígena. De todas maneras, es posible que esta adaptación de historias testamentarias para la celebración del nacimiento del Niño Dios y de la Epifanía tenga aún más entrecruces de diferentes fuentes religiosas, rituales y temáticas.

\section{INTERPRETACIÓN DESDE LA PERS- PECTIVA DE LA TEATRALIDAD ME- DIEVAL}

¿Cuáles podrían ser posibles referentes medievales de esta fiesta realizada en Yucatán? Podríamos de principio proponer algunos elementos formales que están presentes en el Ordo Stellae o en el Ordo Prophetarum ${ }^{18}$. En estas piezas encontramos la presencia de la estrella como elemento de guía para los reyes de Oriente que visitan al Niño Jesús o bien la presentación del linaje de la familia de David. Como comentamos anteriormente, en la fiesta maya se identifica a Isaac como portador de la estrella de Belén.

Otro posible referente podría ser las festividades que aún hoy en día se llevan a cabo en varios puntos de la península ibérica (con evidencias de formatos medievales), como es el caso de la fiesta de los Rapaces, celebrada en el recóndito poblado de Barge, en la región de Tras os montes, Braganza, en Portugal. Esta región es limítrofe a Zamora, (España), donde también se celebra la fiesta del Zangarrón ${ }^{19}$. Esta fiesta portuguesa es una celebración campesina, hecha también en Navidades; en ella también los jóvenes de la localidad juegan a defenderse en batallas de naranjas, disfrazados algunos de ellos como representaciones del mal.

La fiesta yucateca nos ofrece, como uno de sus más importantes símbolos, el manejo del Niño Dios como imagen incorporada dentro del contexto de la representación de pesebre al interior del templo. Es posible, por lo tanto, que podamos indagar, como otra pauta de referente medieval, la arraigada tradición franciscana del Pesebre ${ }^{20}$.

Cabe destacar la manera en que la fiesta en Dzitnup tiene como resolución ritual una procesión final en el interior del templo. Este es un formato poco frecuente en celebraciones religiosas actuales en México y nos remite a la manera en que, en la Europa medieval, se llevaban a cabo procesiones de esta naturaleza. 
Por último, nos parece oportuno tratar de explicar hipotéticamente la integración de personajes veterotestamentarios en una fiesta navideña: es posible también que algún párroco, versado en aspectos teológicos, hubiera hecho esta adecuación para fortalecer la Historia Sacra dentro de una comunidad que, probablemente, tenía arraigada esta festividad (con personajes similares) como parte de un cosmos netamente indígena.

A pesar de que no contamos con ningún antecedente temático de otra fiesta en México o en Europa, no se descarta la posibilidad de que, en algún momento dado, podamos encontrar documentación de alguna pieza de teatro religioso en donde se consigne la convivencia «a-histórica» entre Abraham, Isaac y la figura infante de Cristo.

\section{CONSIDERACIONES FINALES}

La fiesta de Abraham e Isaac en Dzitnup es un evento vivo de múltiples lecturas. Es muy probable que estemos ante un fenómeno de adaptación ritual indígena de un mito cristiano, en donde se conmemora, a través de los personajes de Abraham e Isaac, lo nuevo y lo viejo, el mundo pagano y el mundo sacro. La representación evidencia, a través de los personajes, la manera en que una comunidad ofrece testimonio de adoración y protección a la figura inocente e indefensa del Niño Dios. Los defensores de la amenaza son dos personajes que proceden del mundo del Antiguo testamento, pero que pertenecen en linaje a la cristiandad. Abraham e Isaac son finalmente intermediarios y defensores en esta historia de convivencia entre dos órdenes en contraposición. El Mal es la fuerza que amenaza con la posibilidad de un rapto o de una trasgresión al espacio sacro (el interior de la parroquia), pero esta amenaza no es una figura temible, sino lúdica y jocosa. El Mal transita solamente en el atrio, en el exterior, en el espacio donde puede convivir con lo «viejo», con el orden viejo donde se encuentran los instrumentos musicales y rítmicos indígenas. El Mal, a través de juegos, será dominado por los jóvenes y por los personajes protectores del Niño, el cual reposa en el espacio nuevo, como representación de la nueva deidad, del orden nuevo, de la nueva religiosidad triunfante. Como sucede con algunas danzas de la Conquista guatemaltecas, la comunidad podría también estar conmemorando la transición de la religiosidad indígena a la religiosidad cristiana. En este evento en particular, la batalla no la libran personajes históricos del contexto americano, sino de la historia religiosa cristiana y con la presencia de un elemento más abstracto, el Mal, que puede representar lo antagónico desde las perspectivas tanto nativas como europeas.

Al no contar con las trazas suficientes, resulta complejo dar seguimiento, a través de la his-

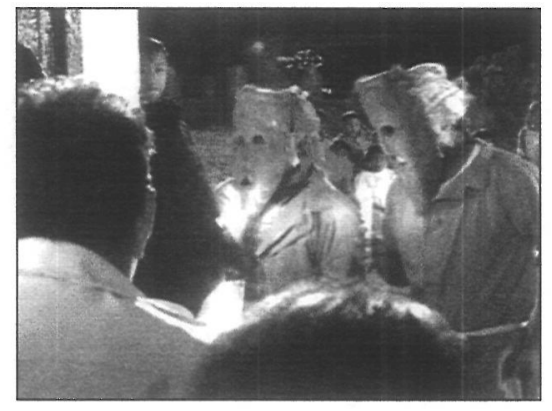

Representación de Abraham e Isaac en Tzinup. Foto de Raquel Araujo. toria colonial de la región, del impacto que las primeras propuestas de cristianización tuvieron entre los indígenas mayas. Sin embargo el Abrabam e Isaac de Dzitnup nos puede ejemplificar de manera clara cómo una comunidad se apropia, con elementos indistintos, de sus particulares necesidades de conmemoración. Este evento nos presenta un escenario (como toda fiesta del estío del hemisferio norte) en donde durante la noche más larga (o vieja) surge la deidad de la nueva luz. El orden nuevo ante el orden viejo. Si lo observamos así, esta fiesta podrá tener, para nuestra mirada, más sentido, más explicaciones, que si se tratara de un simple, espontáneo $\mathrm{y}$ «folklórico» desatino interpretativo de una comunidad. ¿Hasta dónde podríamos encontrar vestigios de una cultura y la otra? ¿Hasta dónde determinar la presencia de algún elemento de origen medieval en una expresión cultural americana? Ofrecemos una exposición general de los elementos de este evento para poder profundizar en un trabajo posterior. Por lo pronto, nos parece oportuno insistir que en el estudio de festividades de esta naturaleza pueden convivir elementos de ritualidades populares autóctonas y elementos supervivientes del mundo medieval.

Indudablemente el Abrabam e Isaac de Dzitnup es una de las fiestas más complejas de las que hemos tenido noticia en el amplio panorama de la ritualidad indígena de nuestro país, y merece, por tanto, incorporarla al estudio de nuestra teatralidad.

\section{BIBLIOGRAFÍA}

Astey, Luis, Dramas litúrgicos del occidente medieval, México, El Colegio de México / CONACYT / ITAM, 1992.

Ciudad Real, Antonio de, Tratado curioso y docto de las grandezas de la Nueva España, México, UNAM, Instituto de Investigaciones Históricas, 1993.
Abraham e Isaac, personajes de una Epifanía en una comunidad indígena de Yucatán GARCÍA GUTIÉRREZ
ÓSCAR ARMANDO 
Frischmann, Donald, «Transformaciones y trascendencia en el arte ritual y escénico de los mayas peninsulares», Investigación Teatral, núm. 5, enero-junio 2004, págs. 9-20.

García Gutiérrez, Óscar Armando, «Los espacios escénicos en Tikal», Cuadernos de Arquitectura Mesoamericana (División de Estudios de Posgrado. Facultad de Arquitectura. UNAM), núm. 6, noviembre 1985, págs. 69-86.

— , «La capilla abierta: espacio, representación y poder institucional en la Nueva España» en Daniel Meyran, Alejandro Ortiz y Francis Sureda (eds.), Teatro y po- der, Perpignan, Presses Universitaires de Perpignan, Collection Études, 2002, págs. 285-296.

Gerhard, Peter, La frontera sureste de la Nueva España, México, UNAM, 1991.

González Cicero, Stella Ma., Perspectiva religiosa en Yucatán, 1517-1571, México, El Colegio de México, 1978.

Massip, Francesc, El teatro medieval, Barcelona, Montesinos, 1992.

Muñoz, Fernando, Teatro maya peninsular, Mérida, Ayuntamiento de Mérida, 2000.

Pérez Sabido, Luis, Bailes y danzas tradicionales de Yucatán, Mérida, DIF-Yucatán, 1983.
Abraham e Isaac personajes de una Epifanía en una comunidad indígena de Yucatán

OSCAR ARMANDO GARCIA GUTIÉRREZ 